\title{
Deposition of Carboxymethylcellulose Coated Zero-valent Iron Nanoparticles onto Silica: Role of Solution Chemistry and Organic Molecules
}

\author{
Revised and resubmitted to: \\ Langmuir \\ June 6, 2010 \\ JULIEN FATISSON ${ }^{1}$, SUBHASIS GHOSHAL ${ }^{2}$, and NATHALIE TUFENKJI ${ }^{*}, 1$ \\ ${ }^{1}$ Department of Chemical Engineering, McGill University, \\ Montreal, Quebec H3A 2B2, Canada \\ ${ }^{2}$ Department of Civil Engineering, McGill University, \\ Montreal, Quebec H3A 2K6, Canada
}

\section{Abstract}

${ }^{*}$ Corresponding Author. Phone: (514) 398-2999; Fax: (514) 398-6678; E-mail: nathalie.tufenkji@mcgill.ca 
Zero-valent iron nanoparticles (nZVI) used in remediation of contaminated subsurface environments are commonly stabilized using polymer coatings. A bottom-up synthesis approach was used to synthesize carboxymethylcellulose (CMC) coated nZVI particles with increased colloidal stability. The influence of water chemistry and selected environmental molecules, namely fulvic acids and rhamnolipids, on the aggregate size and surface charge of the bare and CMC-coated nZVI particles was systematically examined using dynamic light scattering (DLS), nanoparticle tracking analysis (NTA), and laser Doppler velocimetry. Quartz crystal microbalance with energy dissipation monitoring (QCM-D) was used to quantify the deposition rates of bare and CMC-coated nZVI particles onto a silica surface over a broad range of solution ionic strengths and in the presence of naturally occurring molecules. Nanoscale ZVI particle deposition was found to increase with IS for many of the conditions investigated. CMC acted as a better colloidal stabilizer when covalently bound to nZVI particles than when physisorbed onto the nanoparticle surface after particle synthesis. The lowest nanoparticle deposition rates were observed for CMC-coated nZVI in the presence of rhamnolipid biosurfactant.

Keywords: Zero-valent iron nanoparticles, carboxymethylcellulose, rhamnolipid, quartz crystal microbalance, DLVO, nanoparticle tracking analysis. 


\section{Introduction}

In recent years, increasing efforts have been directed towards the development of new engineered nanomaterials for targeted applications. Nanoscale systems have been employed in various commercial products (www.nanotechproject.org), drug delivery applications ${ }^{1,2}$, as well as the development of environmental solutions ${ }^{3,4}$. For example, nanosized zero-valent iron (nZVI) particles have been employed for soil decontamination ${ }^{5}$. Nanoscale ZVI has been found to be effective for the removal of a wide range of water and soil contaminants, including chlorinated solvents $^{5-9}$, nitrates ${ }^{10}$, mercury ${ }^{11}$, arsenic ${ }^{12}$ and several others ${ }^{13-17}$. Field studies have shown that deep injections of nZVI particles are very useful for remediation of dense non-aqueous phase liquids located in natural subsurface environments ${ }^{5}$. The main problem encountered in this type of application is the limited transport of nZVI particles through soils towards the contaminated zone of interest. Bare (unmodified) nZVI particles can aggregate very rapidly due to attractive magnetic forces ${ }^{18-20}$, thereby decreasing their transport potential and possibly their reactivity due to the lessened specific surface area of nZVI aggregates.

Several solutions have been proposed to enhance nZVI transport in natural subsurface environments with a common objective of stabilizing the colloidal suspensions. These include coating nZVI particles with polymeric materials, or modifying their surface with hydrophilic carbon, or embedding them in a silica matrix ${ }^{6,21,22}$.

Different polymers have been used to modify nZVI particle surfaces in an effort to improve nanoparticle stability and mobility, with varying levels of success ${ }^{12,19,21,23-26}$. Saleh et al demonstrated that branched copolymers of poly(methacrylic acid)-block-poly(methyl methacrylate)-block-poly(styrene sulfonate) can greatly improve nZVI particle transport through

packed beds of silica sand and soil ${ }^{23,26}$ for an effective delivery of particles to the site of 
contamination. Tiraferri et $\mathrm{al}^{19}$ used guar gum to coat nZVI particles and observed reduced nanoparticle aggregation and sedimentation. Other studies have compared the effect of different polymers on the stabilization of nZVI suspensions. Phenrat et $\mathrm{al}^{25}$ modified nZVI by adsorption of selected commercially available polymers (i.e., polystyrene sulfonate, poly(acrylic acid) and carboxymethylcellulose) to obtain colloidally stable nZVI suspensions. Using the same polymers, Kim et $\mathrm{al}^{27}$ showed that the higher molecular weight molecules yielded slightly more stable nZVI suspensions. In these previously reported studies, the polymers used for modifying nanoparticle suspensions were physically adsorbed directly onto already formed nZVI particles. This type of binding between the particle and the selected polymer is generally less strong and potentially less effective at stabilization than a chemical bond ${ }^{28}$. In a recent study, He et $\mathrm{al}^{29}$ reported that nZVI particles modified by covalently bound carboxymethylcellulose (CMC) exhibited high transport potential in packed beds of glass beads, sand and soil. Most studies examining the transport and deposition of nZVI particles in model subsurface environments have been conducted using classical packed-bed laboratory experiments ${ }^{6,12,20,22,24,26,27,30}$. More recently, microgravimetric measurements obtained using the quartz crystal microbalance (QCM), have also been shown to be useful in evaluating nanoparticle mobility in model aquatic environments. One advantage of using QCM is that it provides a fundamental understanding of nanoparticle deposition behavior on silica while eliminating the confounding effects of factors such as collector surface roughness and collector geometry. Quevedo and Tufenkji ${ }^{31}$ used this technique to evaluate the interaction of quantum dots with model sand (i.e., silica) surfaces over a wide range of environmentally relevant conditions. In a previous study, we showed that measurements of $\mathrm{TiO}_{2}$ nanoparticle deposition onto silica obtained by QCM with energy dissipation monitoring (QCM-D) were in relatively good agreement with DLVO predictions ${ }^{32}$. Saleh et $\mathrm{al}^{23}$ and Sirk et $\mathrm{al}^{33}$ used QCM-D to confirm the 
effectiveness of different polymer coatings in reducing nZVI deposition onto silica. Hence, QCMD can be a useful tool for investigating the influence of environmental conditions on nanoparticle deposition onto clean and functionalized surfaces.

The purpose of this study is to systematically examine the effect of using CMC as a surfacemodifying polymer on nZVI transport and deposition onto a model sand surface (i.e., silica). QCM-D was used to evaluate the deposition behavior of nZVI particles onto silica over a broad range of solution ionic strengths (IS) using particles that were covalently bonded with CMC during their bottom-up synthesis (referred to as CMC-nZVI hereafter) or physisorbed with CMC by mixing with bare nZVI. To better understand the potential influence of common naturally occurring molecules in groundwater on nZVI transport and deposition, experiments were also conducted in the presence of a model fulvic acid, Suwannee River fulvic acid (SRFA), and a biosurfactant (rhamnolipid) that is commercially available. Biosurfactants such as rhamnolipids can be produced and released by certain species of soil bacteria ${ }^{34,35}$ (e.g., Pseudomonas species). Finally, predictions based on DLVO theory were employed to verify observations made by QCMD.

\section{Materials and Methods}

\subsection{Synthesis of nZVI Particles and Preparation of Nanoparticle Suspensions.}

Zero-valent iron nanoparticles were synthesized by reduction of $\mathrm{Fe}^{2+}$ solution by sodium borohydride under a $\mathrm{N}_{2}$ atmosphere ${ }^{36,37}$. Briefly, ferrous sulfate (Sigma-Aldrich) was dissolved in a 30\% methanol/water solution. In the case of CMC-nZVI, the ferrous sulfate was dissolved in water and mixed with an aqueous solution of $\mathrm{CMC}$ (90 $\mathrm{kDa}$, Sigma-Aldrich), to a final concentration of $0.5 \mathrm{w} / \mathrm{w} \%$. After $30 \mathrm{~min}$ stirring, $\mathrm{NaBH}_{4}$ (Sigma-Aldrich) was added dropwise 
to the iron solution. A black precipitate was formed in both cases (bare nZVI and CMC-nZVI). The ratio $\left[\mathrm{BH}_{4}^{-}\right] /\left[\mathrm{Fe}^{2+}\right]$ was set at 1.5 for synthesis of the bare nZVI while it was 2.0 in the case of the CMC-coated particles. After complete addition of the borohydride, the mixture was left for 30 min before being freeze-dried overnight and finally stored under $\mathrm{N}_{2}$. Similar to the results of He et $\mathrm{al}^{29}$, FTIR analyses revealed that the carboxylate group in the CMC was covalently bonded with the iron surface. The presence of $\mathrm{Fe}(0)$ was confirmed by XPS analyses.

A stock suspension of nZVI (1 g/L) was prepared under a $\mathrm{N}_{2}$ atmosphere by suspending synthesized nZVI powders in $\mathrm{N}_{2}$-purged deionized (DI) water, followed by 30 min of sonication. Suspensions of nZVI (150 mg/L) were prepared by diluting the stock suspension into $\mathrm{N}_{2}$ purged $\mathrm{NaHCO}_{3}$ (Sigma-Aldrich) solutions prepared at different salt concentrations (IS = 1-100 mM) at pH 7.0 \pm 0.1. When the CMC-nZVI particles are re-suspended for experimentation, the final concentration of total CMC is estimated to be approximately $0.1 \mathrm{wt} \%$ when accounting for dilution from synthesis to final suspension. The suspension prepared at $150 \mathrm{mg} / \mathrm{L}$ was kept at room temperature for $30 \mathrm{~min}$ and vortexed at high speed for $30 \mathrm{sec}$ prior to any measurement. The same concentration of nZVI (150 mg/L) was used in all measurements and experiments for relevant comparisons between each technique. Each colloid suspension was prepared in the exact same manner and used within the first 10 minutes following preparation, when all suspensions were found to be relatively stable, for each experimental technique (QCM-D, DLS, NTA, and laser Doppler velocimetry). For our experimental systems, CMC modified nanoparticle suspensions were found to be relatively stable over several hours, whereas bare nZVI were stable for at least 10 minutes, using the above analytical methods.

All chemicals used to prepare solutions were of analytical grade. Suwannee River fulvic acid (SRFA, standard II, IHSS, St-Paul, MN) was dissolved in $\mathrm{N}_{2}$ purged DI water to create a stock 
suspension at $100 \mathrm{mg} / \mathrm{L}$. A $10 \%$ stock mixture of 2 major rhamnolipids (rhamnosyl- $\beta$ hydroxydecanoyl- $\beta$-hydroxydecanoate $\quad\left(\text { Rha- } \mathrm{C}_{10}-\mathrm{C}_{10}\right)_{2}$ and rhamnosyl-rhamnosyl- $\beta$ hydroxydecanoyl- $\beta$-hydroxydecanoate (Rha-Rha- $\left.\mathrm{C}_{10}-\mathrm{C}_{10}\right)^{38}$, Jeneil Biosurfactant Co (Saukville, WI), was used to prepare nZVI suspensions with rhamnolipids. Stock solutions of SRFA and rhamnolipid were used to prepare nZVI suspensions with a final concentration of $2 \mathrm{mg} / \mathrm{L}$ organic matter.

\subsection{Nanoparticle Sizing}

Dynamic Light Scattering (DLS) (Malvern ZetaSizer Nano) and Nanoparticle Tracking Analysis (NTA) (NanoSight NTA2.0 LM20 with a laser output of $30 \mathrm{~mW}$ at $650 \mathrm{~nm}$ ) were used to measure the hydrodynamic diameters of the nZVI particles. The refractive index for nZVI was set at $2.87^{20}$. For NTA measurements, mean square displacements of single particles were determined by tracking the scattered light followed by analysis using the NanoSight software. Each data point for NTA represents the average for 150 counted particles. Additional details regarding the different nanoparticle sizing techniques are discussed in the literature ${ }^{39}$. Results are presented as the means of triplicates obtained with freshly prepared samples. In each run, fresh samples at the same nZVI concentration $(150 \mathrm{mg} / \mathrm{L})$ were injected and measurements were performed following each injection. The stability of the nZVI suspensions over the timescale of the experiments was also confirmed by DLS (data not shown).

\subsection{Nanoparticle Imaging}

Transmission electron microscopy (TEM) was used to obtain high resolution images of the bare and CMC-nZVI particles under selected conditions. Samples were prepared by placing a drop of 
the nanoparticle suspension on a Formvar grid, which was left to air-dry overnight prior to analysis. Measurements were performed on a TECNAI microscope equipped with an AMT CCD camera and operating at $120 \mathrm{kV}$ with a $\mathrm{LaB}_{6}$ filament.

\subsection{Electrokinetic Characterization of nZVI Particles}

Electrophoretic mobility (EPM) of the nanoparticles in $\mathrm{NaHCO}_{3}$ was characterized by Laser Doppler velocimetry (ZetaSizer Nano ZS, Malvern). EPM measurements were repeated using at least three different samples (prepared on different days at $150 \mathrm{mg} / \mathrm{L}$ ) at $25.0 \pm 0.2^{\circ} \mathrm{C}$. The strength of the applied electrical field (E) was $4.8 \pm 0.1 \mathrm{~V}$. Measured EPMs were converted to $\zeta$-potentials using the Smoluchowski equation ${ }^{40}$.

\subsection{Quartz Crystal Microbalance with Dissipation (QCM-D) Measurements.}

QCM-D measurements were performed with a Q-Sense E4 unit (Q-Sense AB, Göteborg, Sweden) by simultaneously monitoring the changes in frequency $(\Delta f)$ and energy dissipation $(\Delta D)$ of a 5 MHz silica-coated QCM-D crystal (QSX-303). The QCM-D crystal was excited to oscillate in the thickness-shear mode at its fundamental resonance frequency $\left(f_{0}=5 \mathrm{MHz}\right)$, at odd overtones $(n=$ 3,5 , or 7) by applying a radio-frequency voltage across the electrodes. Energy dissipation of the crystal was periodically recorded by measuring the exponentially dissipated sinusoidal voltage signal over the crystal caused by switching off the voltage applied to the piezoelectric oscillator. The Q-Sense software (QSoft) was then used to acquire the $D$ factor defined as follows:

$$
D=\frac{E_{\text {dissipated }}}{2 \pi E_{\text {stored }}}
$$

where $E_{\text {dissipated }}$ is the energy lost during one oscillation cycle and $E_{\text {stored }}$ is the total energy stored in the oscillator. The $D$ factor provides information on some of the viscoelastic properties of the 
deposited layer. While the $D$ factor can also be used to indirectly monitor deposition kinetics ${ }^{32}$, the frequency shift $(\Delta f)$ is a direct indication of the mass deposited on the crystal surface $(\Delta m)$, as described by the Sauerbrey ${ }^{41}$ relationship:

$$
-\Delta f=\frac{1}{n C} \Delta m
$$

where the mass sensitivity constant, $C$, is equal to $17.7 \mathrm{ng} \cdot \mathrm{cm}^{-2} \mathrm{~Hz}^{-1}$ when $f=5 \mathrm{MHz}$. This relationship can be used to determine mass adsorbed onto a surface in the case of homogeneous, very thin and quasi-rigid layers. Hence, Equation 2 may not be valid under the conditions of the present study, where the deposited film of nanoparticles may be non-uniform. In order to go beyond the Sauerbrey approximation, the $f$ and $D$ experimental data were analyzed to evaluate the mass-based deposition rates using the model developed by Voivona et $\mathrm{al}^{42,43}$ hypothesizing that the film is a homogeneous and isotropic viscoelastic layer. The Q-sense software (QTools) was used to model the raw data. Since deposition of nanoparticles may form non-homogenous layers, the mass-based deposition rates (Figures 5 and 7) are presented later in the paper simply as orderof-magnitude estimates.

A clean silica-coated quartz crystal was mounted into a clean QCM-D flow chamber, stabilized at $25.00 \pm 0.02^{\circ} \mathrm{C}$, with only one side in contact with the working solution. A background $\mathrm{N}_{2}$-purged $\mathrm{NaHCO}_{3}$ particle-free solution ( $\mathrm{pH}$ 7) prepared at the IS of interest was injected into the flow cell $(0.40 \mathrm{~mL} / \mathrm{min})$ until a stable baseline was reached. Subsequently, a suspension of nZVI particles suspended in the same electrolyte was injected into the flow chamber $(0.40$ $\mathrm{mL} / \mathrm{min}$ ) for at least $10 \mathrm{~min}$. Frequency and dissipation shifts were continuously recorded during the entire experiment. QCM-D experiments were repeated using at least three different samples prepared on different days. After each experiment, the crystals, chambers, and tubing were rinsed with at least $25 \mathrm{~mL}$ of $2 \%$ Hellmanex (Fisher Scientific), and at least $30 \mathrm{~mL}$ of DI. The crystals 
were further cleaned by soaking in $2 \%$ Hellmanex overnight, rinsed with DI water and dried under $\mathrm{N}_{2}$ before any additional measurement. Because the $D$ factor is a ratio of energies (eq 1), it is dimensionless and is reported as $10^{-6}$ dissipation units (DU).

\section{Results and Discussion}

\subsection{Characterization of nZVI in the Presence and Absence of CMC.}

\subsubsection{Sizes of Nanoparticles and their Aggregates for Different Solution Chemistries.}

Because nanoparticle size plays a significant role in colloid deposition onto collector surfaces ${ }^{44-47}$, it is of interest to characterize the nZVI suspensions used in this study over the wide range of solution chemistries examined. This is particularly important in the case of nZVI particles as they can readily aggregate ${ }^{18,23,33}$. Certain difficulties arise when characterizing nanoparticle suspensions due to the inherent limitations of different techniques which can lead to varying sizing results depending on the method utilized ${ }^{39}$. An approach using multiple techniques seems to be most promising for nanoparticle size characterization ${ }^{39}$.

TEM may lead to multiple artefacts regarding the aggregation state of nanoparticles; electrolyte evaporation during TEM sample preparation increases nanoparticle concentration locally and enhances particle aggregation ${ }^{39}$. Nonetheless, nominal particle size can be determined using this technique. Imaging of prepared bare nZVI suspensions provided a chain-like structure, as expected for these unmodified particles (Figure S1a). Other researchers working with nZVI suspensions prepared using a similar synthesis approach previously presented comparable TEM images $^{10,17,48}$. Analysis of over $100 \mathrm{nZVI}$ nanoparticles in TEM images prepared using nZVI suspensions in polymer-free $\mathrm{NaHCO}_{3}$ electrolyte revealed a mean diameter of $77 \pm 15 \mathrm{~nm}$ for synthesized bare nZVI particles. 
Due to their magnetic properties, nZVI can easily form aggregates ${ }^{18,25}$. Particle size was evaluated using two other techniques that can be carried out while maintaining the samples under a $\mathrm{N}_{2}$ atmosphere during the measurement. Figures $1 \mathrm{a}$ and $1 \mathrm{~b}$ present the mean diameters of bare nZVI obtained by DLS and NTA, respectively, at different IS, in the presence of SRFA or CMC added to the solution.

Based on the DLS measurements (Figure 1a), the greatest size of the bare nZVI particles is observed in simple electrolyte (between 400 and $600 \mathrm{~nm}$ ). The addition of SRFA tends to decrease the average particle size to $\sim 190 \mathrm{~nm}$ over the entire range of IS examined. Free CMC has a greater effect in stabilizing the nZVI suspension; the average particle size for this treatment measured by DLS is approximately $135 \mathrm{~nm}$. The decreases in particle size reflect a lower extent of aggregation achieved during the 30 minutes contact time with the different organic molecules. In order to complete nZVI size characterization, NTA measurements were also performed and are

presented in Figure 1b. In both the presence and absence of SRFA, NTA measurements reveal an average particle size of $\sim 316 \mathrm{~nm}$, whereas the addition of free CMC leads to lower nZVI aggregate size (below $200 \mathrm{~nm}$ ). Phenrat et $\mathrm{al}^{25}$ also reported a decrease in the hydrodynamic radius with CMC adsorption (262 nm) when compared with bare nZVI particles (360 nm), demonstrating the stabilizing effect of CMC.

[FIGURE 1 HERE]

Figure 2 presents DLS and NTA measurements of CMC-nZVI particles. Figures 2a and 2b show the mean diameters of CMC-nZVI particles measured by DLS and NTA respectively, in the absence and presence of SRFA or rhamnolipid. At low IS (3 and $10 \mathrm{mM}$ ), the addition of 
SRFA or rhamnolipid to the CMC-nZVI particle suspension improved the stability of the nanoparticle suspension. At higher IS, the addition of these organic molecules did not cause any statistically significant effect on CMC-nZVI particle size. The chain-like structure previously observed for bare nZVI also appears in the case of the CMC-nZVI (Figure S1b), most likely due to locally increased particle concentration resulting in enhanced magnetic attractive forces during the drying step used in TEM sample preparation. The image also reveals the presence of free and particle-associated CMC in the sample. Analysis of over 100 nanoparticles in TEM images revealed a mean diameter of $94 \pm 25 \mathrm{~nm}$ for CMC-nZVI particles.

[FIGURE 2 HERE]

\subsubsection{Electrokinetic Characterization of nZVI Particles.}

Figure 3 shows $\zeta$-potentials calculated from electrophoretic mobility (EPM) measurements conducted on bare and CMC-nZVI particle suspensions in different water chemistries. Over all conditions, nanoparticle $\zeta$-potentials become less negative with increasing IS, due to an increase in charge screening. Nanoparticle $\zeta$-potentials determined for bare nZVI (Figure 3a) in the absence of organic polymers (between -15 and $-25 \mathrm{mV}$ ) are comparable to values previously reported for nZVI particles at near-neutral $\mathrm{pH}$ (e.g., $-29.6 \mathrm{mV}$ in $1 \mathrm{mM} \mathrm{NaHCO}_{3}{ }^{23},-30 \mathrm{mV}$ in $1 \mathrm{mM}$

$\mathrm{NaHCO}_{3}{ }^{26}$ ). In the case of bare nZVI (Figure 3a), the particle charge is more negative in the presence of SRFA, suggesting that the fulvic acid readily associates with the bare particle surface. The bare nanoparticle surface charge becomes even more negative in the presence of free CMC and is comparable to that determined for CMC-nZVI particles (Figure 3b), suggesting that the nature of the CMC bond to nZVI (physisorbed versus covalently bound) does not play an important 
role in the measured particle EPM. Saleh and co-workers ${ }^{23,26,33}$ and Tiraferri et al ${ }^{19}$ also observed more negative nZVI $\zeta$-potentials in the presence of copolymers or poly(sodium aspartate). While the addition of SRFA does not seem to significantly influence the surface charge of CMC-nZVI particles, the addition of rhamnolipids tends to make them slightly more negative, especially above $10 \mathrm{mM}$ (Figure 3b). The $\zeta$-potential and DLS size data are used later in the paper to evaluate DLVO interaction energy profiles for interaction of the nZVI particles with silica collector surfaces used in the QCM-D experiments.

[FIGURE 3 HERE]

\subsection{Bare and CMC-nZVI Deposition Behavior onto Silica.}

\subsubsection{Frequency and Dissipation Signals During nZVI Deposition onto Silica.}

Representative QCM-D measurements made during injection of a bare nZVI particle suspension into a QCM-D flow chamber are presented in Figure 4. During phase I of the experiment, $\mathrm{N}_{2^{-}}$ purged background electrolyte is injected to obtain a stable baseline. When a suspension of bare nZVI particles in the same purged electrolyte is injected (phase II), a rapid relatively linear decrease in frequency, in conjunction with a linear increase in dissipation are observed. These shifts in $f$ and $D$ correspond to the deposition of bare nZVI particles onto the clean silica-coated crystal surface. After a few minutes, the $f$ and $D$ signals become non-linear (phase III). Similar plots where obtained for all other conditions. This observation may be attributed to a phenomenon commonly referred to as "ripening" whereby suspended nZVI particles deposit onto particles that have previously attached onto the silica surface. The change in slope between phases II and II is not as obvious in the $f$ measurements as it is in the $D$ signals. This increased sensitivity of the $D$ measurement was also noted previously ${ }^{32}$. 


\section{[FIGURE 4 HERE]}

By measuring the change in $f$ or $D$ as a function of time, one can evaluate the change in deposited mass on the crystal surface with time; namely, the nanoparticle deposition rate onto the silica surface. Hence, nZVI particle deposition kinetics can be determined by evaluating the initial slope in the frequency and dissipation shifts ( $f_{\text {slope }}$ and $D_{\text {slope, }}$ respectively) from the QCM-D experiments. Because of the noted ripening effect at latter times (e.g., Figure 4), the nZVI initial particle deposition kinetics onto the clean silica surface were determined by considering the measurements obtained within the first 5 minutes of injection of the nanoparticle suspension into the QCM-D flow chamber (i.e., during phase II). Control experiments with particle-free electrolytes were conducted and did not show any measurable deposition of CMC, SRFA or rhamnolipids under the conditions tested. This approach for evaluating nanoparticle deposition kinetics has also been used in previous studies examining deposition of $\mathrm{TiO}_{2}$ nanoparticles ${ }^{32}$, fullerene aggregates ${ }^{49,50}$, and quantum dots ${ }^{31}$.

\subsubsection{Effect of CMC on the Deposition of nZVI Particles onto Silica.}

Figures $5 \mathrm{a}$ and $5 \mathrm{~b}$ present the measured nZVI deposition rates as the negative value of $f_{\text {slope }}\left(-f_{\text {slope }}\right)$ and the $D_{\text {slope }}$ over a wide range of IS, respectively. From these $f_{\text {slope }}$ and $D_{\text {slope }}$ values, deposited mass rates ( $\left.m_{\text {slope }}\right)$ were estimated using the QTools software (Figure $5 \mathrm{c}$ ). Inspection of Figures $5 \mathrm{a}, \mathrm{b}$ and $\mathrm{c}$ shows that the general trend for each set of experiments is similar when comparing

values of $-f_{\text {slope }}, D_{\text {slope }}$ and $m_{\text {slope. }}$. Thus, the discussion that follows will focus on a description of values of $-f_{\text {slope }}$ and $D_{\text {slope }}$ alone. In each series of experiments, the deposition rate of nZVI particles 
onto the silica surface increases with IS (i.e., $-f_{\text {slope }}$ and $D_{\text {slope }}$ are increasing with IS). The nanoparticles are negatively charged at $\mathrm{pH} 7$ (Figure 3) and the clean silica surface is also negatively charged at this $\mathrm{pH}^{51}$. Hence, repulsive electrostatic forces are expected to predominate the nanoparticle-silica interactions. As IS increases, the thickness of the diffuse double layer decreases due to more effective charge screening, thus attenuating the electrostatic repulsion between nZVI particles and the silica surface. Hence, increased nZVI deposition (larger values of $-f_{\text {slope }}$ and $\left.D_{\text {slope }}\right)$ onto the silica surface is observed at higher IS. This observation is in agreement with earlier nanoparticle transport and deposition studies ${ }^{31,32}$. Saleh et al ${ }^{26}$ also observed an increase in nZVI deposition rates (i.e., sticking coefficient) with increasing solution salt concentration using sand-packed columns. In another study ${ }^{23}$, these researchers demonstrated that higher ion content lead to a decrease of transport of bare and polymer coated nZVI particles through a sand column. Sirk et $\mathrm{al}^{33}$ also noted an increase in adhered mass on silica at higher IS for polymer coated nZVI particles.

\section{[FIGURE 5 HERE]}

The data shown in Figure 5 also brings insight on the effect of CMC on nZVI deposition kinetics. In the case of bare (unmodified) nZVI particles, the addition of free CMC (at 0.1 wt $\%$ ) was not effective at preventing particle deposition onto the silica surface. Moreover, QCM-D experiments conducted using free CMC alone (no particles, $0.1 \%$ free $\mathrm{CMC}$ ) confirmed that free CMC does not readily adsorb onto silica under the conditions investigated (data not shown). Hence, attempts to directly coat the silica surface with free CMC did not result in an important stabilizing effect (Figure 5, symbols). We noted a significant effect when CMC is covalently 
bound to the nZVI particle surface (Figure 5). Measured values of $-f_{\text {slope }}$ and $D_{\text {slope }}$ are lowest over the entire range of IS for CMC-nZVI particles. Thus, nZVI deposition onto silica is best hindered when CMC is covalently bound to the nanoparticle surface (versus physisorbed CMC).

Our data suggest that a mechanism of electrosteric stabilization is the most likely mechanism which dominates the nZVI particle-surface interactions. Previous investigations demonstrated that the noted decrease in nZVI particle deposition after polymer adsorption was partly due to electrosteric repulsion ${ }^{25,26,33}$. A recent reactivity study ${ }^{8}$ of modified nZVI by physisorbed CMC suggests that the thickness of a $90 \mathrm{kDa}$ CMC layer on the particle surface is approximately $7 \mathrm{~nm}$. In the current study, DLS measurements of the free CMC polymer yield an equivalent spherical diameter of $\sim 15 \mathrm{~nm}$, whereas CMC thickness estimated from TEM images ranges between 10 and $20 \mathrm{~nm}$ for CMC-nZVI. The extent of steric repulsion increases with polymer thickness. By considering that $\mathrm{CMC}$ physisorption seems to have led to a thinner layer of CMC coating than for CMC covalently bound to the nZVI particle surface, steric repulsion would then be enhanced in the latter case, thereby explaining the noted lower particle deposition rates observed for the CMC-coated nZVI particles (Figure 5). The lower deposition obtained for CMC-nZVI particles may also be explained by the fact that covalent CMC coating may have led to better particle surface coverage than physisorbed CMC.

As mentioned previously, nZVI particle deposition onto the silica surface is expected to be unfavorable under the solution conditions investigated in this study. However, the results shown in Figure 5 indicate that both bare and CMC-coated nZVI can deposit onto silica at all salt concentrations examined. To better understand the interaction forces and mechanisms controlling nZVI particle deposition onto the silica surface, particle-surface interaction energy profiles that 
take into account repulsive electrical double layer, attractive van der Waals, and repulsive steric interactions were evaluated.

\section{[FIGURE 6 HERE]}

Figure 6 presents calculated interaction energy profiles that consider the sum of electrical double layer, van der Waals, and repulsive steric forces, where the nZVI-silica system is treated as a sphere-plate interaction. Size measurements obtained by DLS (Figures 1a and 2a), as well as calculated nanoparticle $\zeta$-potentials (Figure 3) were used in the model calculations. Surface potentials for the silica collector were taken from Bergna and Roberts ${ }^{51}$ and extrapolated from the data of Walker et al ${ }^{52}$. The van der Waals contribution was estimated using the equation described by Gregory ${ }^{53}$ and the electrical double layer contribution from the equation described by Hogg et $\mathrm{al}^{54}$, while the steric contribution was calculated according to the de Gennes equation ${ }^{55}$. The Hamaker constant $\left(1.6 \times 10^{-20} \mathrm{~J}\right)$ used in the calculations was evaluated by using $6 \times 10^{-20} \mathrm{~J}, 8 \times 10^{-21}$ $\mathrm{J}$ and $1 \times 10^{-19} \mathrm{~J}$ as Hamaker constants for silica, water, and iron, respectively ${ }^{18,25,56}$. In the case of bare nZVI suspended in simple electrolyte (i.e., in the absence of organic molecules), the steric contribution is nonexistent and the DLVO profiles consider the sum of van der Waals and electrical double layer interactions alone. For this case, at low IS (3 mM), an energy barrier is present (Figure 6a), thus limiting particle deposition, as observed by the low values of $-f_{\text {slope }}$ and $D_{\text {slope }}$ (Figure 5). As IS increases, the height of the energy barrier decreases and it disappears completely at high IS (100 mM). Accordingly, nZVI particle deposition increases with increasing salt concentration (Figure 5). 
Figure $6 \mathrm{~b}$ presents interaction energy profiles predicted for CMC-nZVI deposition onto clean silica, where the steric contribution was evaluated using a CMC polymer layer thickness of 14.4, 13.7 and $10.9 \mathrm{~nm}$ for 3,10 and $100 \mathrm{mM}$ IS conditions, respectively, for covalently bound CMC (based on triplicate measurements). Steric interactions due to the polymeric CMC coating result in the presence of a substantial energy barrier (on the order of 100,000kT) at all IS. Nevertheless, increased deposition is observed at the higher salt concentrations examined (Figure 5). Differences in the predicted heights of the interaction energy barrier between bare and CMCnZVI are quite high (tens of $k T$ versus hundreds of thousands of $k T$, respectively) (Figure S2a). Depending on the IS considered, values of $-f_{\text {slope }}$ decrease by a factor of $\sim 2$ when comparing bare nZVI and CMC-nZVI, while values of $D_{\text {slope }}$ are approximately 4-fold lower in the presence of covalently bound CMC (Figure 5). These noted variations in calculated nanoparticle deposition rates when comparing values of $f_{\text {slope }}$ and $D_{\text {slope }}$ have previously been reported ${ }^{32}$ and are likely associated with increased sensitivity of the dissipation measurements in contrast to the frequency measurements. Although the DLVO model calculations that include steric interactions predict a very high energy barrier for nanoparticle deposition, the CMC-nZVI still deposit on the silica surface. To evaluate whether the nanoparticles are being retained in the secondary energy minimum of the particle-collector interaction energy profile, Figure S2b presents the calculated depths of the secondary energy minimum based on the DLVO profiles in Figure 6. The secondary energy wells are very shallow for both bare and CMC-nZVI particles, suggesting that nanoparticle deposition under these conditions is likely not controlled by secondary minimum retention, but rather, it may be governed by other factors, such as retention on surface charge heterogeneities of the $\mathrm{SiO}_{2}$ collector surface. It should be noted that the DLVO calculations presented in Figure 6 are not always in agreement with the results of the QCM-D measurements; for example, the 
nanoparticle deposition rates evaluated for bare nZVI are on the same order of magnitude as those measured for CMC-nZVI, yet the model predicts orders of magnitude differences in the heights of the energy barrier. These variations between model predictions and experimentally observed behavior may be attributed to imperfections in the experimental system (e.g., charge heterogeneities or defects on particle or collector surfaces).

\subsubsection{Effect of Environmental Organic Molecules on the Deposition of nZVI Particles onto Silica}

As nZVI are injected and transported through soils to the contaminated site for remediation, it is environmentally relevant to evaluate the influence of naturally occurring molecules (such as fulvic acids and biosurfactants) on nZVI particle transport. Fulvic acids are fractionated from humic substances resulting from the biological decomposition of dead cells. Compared to humic acids, fulvics are hydrosoluble in the whole range of $\mathrm{pH}$ due to their relatively low molecular weight $(\sim 1.3 \mathrm{kDa})^{57,58}$. Rhamnolipids can also be considered as environmental molecules that may influence particle transport in the natural subsurface environment, as they are secreted by soil

organisms. Rhamnolipids have also been used in bioremediation applications ${ }^{59-61}$. The molecular weight of rhamnolipids is approximately $600 \mathrm{~g} / \mathrm{mol}$, which is lower than for fulvic acids $(\sim 1300$ $\mathrm{g} / \mathrm{mol}$ ). The effect of these two naturally occurring organic molecules on the transport of nZVI particles was examined by QCM-D.

Figure 7 presents the influence of the selected environmental molecules on nZVI particle deposition rates at different IS. In the presence of SRFA, nanoparticle deposition rates determined for bare nZVI seem to be slightly higher than those measured for CMC-nZVI particles. Addition of $2 \mathrm{mg} / \mathrm{L}$ of rhamnolipid to CMC-nZVI suspensions results in the lowest values of $-f_{\text {slope }}$ and $D_{\text {slope. }}$ Values of $m_{\text {slope }}$ were evaluated using the QTools software from measured values of $-f_{\text {slope }}$ 
and $D_{\text {slope, }}$ and are presented in Figures $7 \mathrm{c}$ and $7 \mathrm{~d}$. Figure $7 \mathrm{~d}$ highlights the additional stabilizing effect of rhamnolipid when added to the CMC-nZVI suspensions. Hence, this finding suggests that transport of CMC-nZVI would be greatly enhanced in natural environments where rhamnolipid is present. Comparison of the values presented in Figures 5 and 7 shows that addition of the model fulvic acid to bare nZVI particle suspensions tends to decrease nanoparticle deposition onto silica. This could be explained by the fact that fulvic acids made the bare nZVI surface charge more negative (Figure 3), thereby increasing electrostatic repulsion between the nanoparticles and the silica surface. Steric stabilization is also likely contributing in this case. Johnson et al ${ }^{30}$ observed an enhancement of bare nZVI particle mobility through silica sand when natural organic matter (NOM) was added to the particle suspensions. Kretzschmar and Sticher ${ }^{62}$ also noted a decrease in nanoparticle deposition with increasing concentration of humics when examining sub-micron-sized hematite colloids. The effect of NOM on colloidal stability was also investigated and demonstrated for other colloids such as iron oxide nanoparticles ${ }^{63}$, carbon nanotubes $^{64}$, gold nanoparticles ${ }^{65}$, and polystyrene latex ${ }^{46}$. Figure $3 \mathrm{~b}$ revealed that $\zeta$-potentials of CMC-nZVI particles were very similar in the absence and in the presence of SRFA. Values of $f_{\text {slope }}$ and $D_{\text {slope }}$ obtained in both cases (Figures 5 and 7 ) are also very similar. These results suggest that the transport of CMC-nZVI particles seems generally unaffected by the addition of SRFA, at the concentration used here. In contrast, the deposition rates of bare (unmodified) nZVI particles on silica were significantly lower in the presence of SRFA. This observation can be explained by the presence of the CMC coating at the nZVI surface, which may be preventing or attenuating nanoparticle interactions with SRFA through electrostatic and/or steric effects.

[FIGURE 7 HERE] 
The deposition rate of the CMC-nZVI particles onto the silica surface was found to be lowest in the presence of a biosurfactant (rhamnolipid). Measurements of EPM, converted to $\zeta$ potentials (Figure 3b), revealed that addition of rhamnolipid to the CMC-nZVI suspension renders the particles more negative. Hence, greater repulsive electrosteric interactions with the silica surface are expected in the presence of rhamnolipid, thereby resulting in lower nanoparticle deposition rates. DLS measurements of free CMC in solution revealed a $25 \%$ increase in polymer size in the presence of rhamnolipid when compared to free CMC alone. In contrast, similar measurements of CMC size in the presence and absence of SRFA revealed no changes in polymer size when the fulvic acid was present. These observations suggest stronger interactions between CMC and rhamnolipid versus CMC and SRFA. This enhanced affinity of the rhamnolipid for the CMC would explain the improved electrosteric stabilization observed for this treatment which led to decreased particle deposition rates for CMC-nZVI particles (Figure 7). Because of their relatively small molecular weight, the rhamnolipids may also act to stabilize the CMC-nZVI particles by covering possible defects (gaps) in the CMC coating of the nZVI particles.

Figures $6 \mathrm{c}, \mathrm{d}$ and e show the predicted DLVO interaction energy profiles (including steric interactions) for the interaction of bare and CMC-coated nZVI with a silica surface in the presence of environmental molecules. Energy barrier maxima and secondary energy minima determined from these calculations are plotted against IS in Figures S3a and S3b, respectively. The addition of $2 \mathrm{mg} / \mathrm{L}$ SRFA to the bare nZVI suspension results in a significant increase in the height of the repulsive energy barrier (Figure 6c), when compared to the macromolecule-free bare nZVI suspension (Figure 6a). Accordingly, comparison of Figures 5 and 7 reveals lower deposition rates (i.e., values of $-f_{\text {slope }}$ and $D_{\text {slope }}$ ) for bare nZVI particles in the presence of SRFA. We note 
enhanced deposition of bare nZVI particles at higher IS in the presence of $2 \mathrm{mg} / \mathrm{L}$ SRFA (Figure 7). In contrast, deposition of the CMC-nZVI particles does not seem to change significantly with IS in the presence of the fulvic acid or the rhamnolipid. This finding suggests that steric stabilization resulting from interaction of the organic molecules with the CMC-coated nanoparticles is the governing mechanism controlling the deposition of these particles onto the silica surface.

\section{Conclusions}

The deposition behavior of bare and CMC-modified nZVI particles onto silica surfaces was examined over a broad range of solution chemistries using QCM-D. The rates of change of QCMD crystal resonance frequency and dissipation were used as critical parameters to evaluate nZVI particle deposition rates onto silica. Solution salt concentration was generally found to affect nZVI particle deposition, except for CMC-nZVI in the presence of the organic molecules. While nZVI particle size did not change significantly with solution IS, EPM measurements revealed a decrease in the absolute particle surface charge as IS increased from 3 to $100 \mathrm{mM}$ for all conditions investigated.

Two approaches were used to modify nZVI particle surfaces; in the first case, CMC was physically adsorbed to the particle surface after its synthesis, whereas in the second case, CMC was allowed to covalently bind onto the particle surface during particle synthesis. Results of QCM-D deposition studies showed that covalent binding of CMC during nZVI particle synthesis was a better approach for creating stable nZVI suspensions. Analysis of electrokinetic data along with QCM-D results for each condition suggested that electrosteric repulsion can play a considerable role in nZVI colloid stabilization by CMC. The results of our study show that 
naturally occurring organic molecules (in this case, a model fulvic acid and a model biosurfactant) can have varying effects on bare, physisorbed-CMC-, and covalently-bound-CMC-nZVI particles. The data further suggest that it is important to take into account the influence of steric interactions when considering the transport and deposition behavior of nanoparticles in the presence of such organic molecules. Under the conditions tested here, the lowest deposition rate for nZVI particles onto silica was observed when nZVI particles were covalently modified with CMC and suspended in the presence of rhamnolipid. 


\section{Acknowledgements}

This work is supported by the Natural Sciences and Engineering Research Council of Canada (NSERC Strategic Grant no. 365253), Golder Associates Ltd., the Fonds Quebecois de la Recherche sur la Nature et les Technologies (FQRNT), l'Institut (Robert Sauve) de Recherche sur la Santé et la Sécurité au Travail (IRSST) and the Canada Research Chairs (CRC) program. The authors acknowledge K.J. Wilkinson (U. Montreal) for use of NTA, and A. Moores, M. C. Cirtiu and T. Raychoudhury (McGill) for assistance with $n Z V I$ synthesis. 


\section{References}

1. Beaux, M. F., II; McIlroy, D. N.; Gustin, K. E., Expert Opin. Drug Delivery 2008, 5, (7), 725-735.

2. $\quad$ Suri, S. S.; Fenniri, H.; Singh, B., J. Occup. Med. Toxicol. (London, U. K.) 2007, 2.

3. Obare, S. O.; Meyer, G. J., J. Environ. Sci. Health, Part A: Toxic/Hazard. Subst. Environ. Eng. 2004, A39, (10), 2549-2582.

4. $\quad$ Theron, J.; Walker, J. A.; Cloete, T. E., Crit. Rev. Microbiol. 2008, 34, (1), 43-69.

5. Zhang, W.-X., Journal of Nanoparticle Research 2003, 5, (3-4), 323-332.

6. Zhan, J.; Zheng, T.; Piringer, G.; Day, C.; McPherson, G. L.; Lu, Y.; Papadopoulos, K.; John, V. T., Environ. Sci. Technol. 2008, 42, (23), 8871-8876.

7. Song, H.; Carraway, E. R., Environ. Sci. Technol. 2005, 39, (16), 6237-6245.

8. $\quad$ Phenrat, T.; Liu, Y.; Tilton, R. D.; Lowry, G. V., Environ. Sci. Technol. 2009, 43, (5), 1507-1514.

9. Choi, H.; Agarwal, S.; Al-Abed, S. R., Environ. Sci. Technol. 2009, 43, (2), 488-493.

10. Lin, K.-S.; Chang, N.-B.; Chuang, T.-D., Science and Technology of Advanced Materials 2008, 9, (2), No pp given.

11. Weisener, C. G.; Sale, K. S.; Smyth, D. J. A.; Blowes, D. W., Environ. Sci. Technol. 2005, 39, (16), 6306-6312.

12. Kanel, S. R.; Nepal, D.; Manning, B.; Choi, H., Journal of Nanoparticle Research 2007, 9, (5), 725735.

13. Miehr, R.; Tratnyek, P. G.; Bandstra, J. Z.; Scherer, M. M.; Alowitz, M. J.; Bylaska, E. J., Environ. Sci. Technol. 2004, 38, (1), 139-147.

14. Zhang, Y.; Wang, J.; Amrhein, C.; Frankenberger, W. T., Jr., Journal of Environmental Quality 2005, 34, (2), 487-495.

15. Hori, H.; Nagaoka, Y.; Yamamoto, A.; Sano, T.; Yamashita, N.; Taniyasu, S.; Kutsuna, S.; Osaka, I.; Arakawa, R., Environ. Sci. Technol. 2006, 40, (3), 1049-1054.

16. Jia, Y.; Breedveld, G. D.; Aagaard, P., Chemosphere 2007, 69, (9), 1409-1418.

17. Manning, B. A.; Kiser, J. R.; Kwon, H.; Kanel, S. R., Environ. Sci. Technol. 2007, 41, (2), 586-592.

18. Phenrat, T.; Saleh, N.; Sirk, K.; Tilton, R. D.; Lowry, G. V., Environ. Sci. Technol. 2007, 41, (1), 284290. 
19. Tiraferri, A.; Chen, K. L.; Sethi, R.; Elimelech, M., Journal of Colloid and Interface Science 2008, 324, (1-2), 71-79.

20. Phenrat, T.; Kim, H.-J.; Fagerlund, F.; Illangasekare, T.; Tilton, R. D.; Lowry, G. V., Environ. Sci. Technol. 2009, 43, (13), 5079-5085.

21. Saleh, N.; Phenrat, T.; Sirk, K.; Dufour, B.; Ok, J.; Sarbu, T.; Matyjaszewski, K.; Tilton, R. D.; Lowry, G. V., Nano Letters 2005, 5, (12), 2489-2494.

22. Schrick, B.; Hydutsky, B. W.; Blough, J. L.; Mallouk, T. E., Chemistry of Materials 2004, 16, (11), 2187-2193.

23. Saleh, N.; Sirk, K.; Liu, Y.; Phenrat, T.; Dufour, B.; Matyjaszewski, K.; Tilton, R. D.; Lowry, G. V., Environmental Engineering Science 2007, 24, (1), 45-57.

24. Yang, G. C. C.; Tu, H.-C.; Hung, C.-H., Separation and Purification Technology 2007, 58, (1), 166172.

25. Phenrat, T.; Saleh, N.; Sirk, K.; Kim, H.-J.; Tilton, R. D.; Lowry, G. V., Journal of Nanoparticle Research 2008, 10, (5), 795-814.

26. Saleh, N.; Kim, H.-J.; Phenrat, T.; Matyjaszewski, K.; Tilton, R. D.; Lowry, G. V., Environ. Sci. Technol. 2008, 42, (9), 3349-3355.

27. Kim, H.-J.; Phenrat, T.; Tilton, R. D.; Lowry, G. V., Environ. Sci. Technol. 2009, 43, (10), 38243830 .

28. He, F.; Zhao, D.; Liu, J.; Roberts, C. B., Industrial \& Engineering Chemistry Research 2007, 46, (1), 29-34.

29. He, F.; Zhang, M.; Qian, T.; Zhao, D., Journal of Colloid and Interface Science 2009, 334, (1), 96102.

30. Johnson, R. L.; O'Brien Johnson, G.; Nurmi, J. T.; Tratnyek, P. G., Environ. Sci. Technol. 2009, 43, (14), 5455-5460.

31. Quevedo, I. R.; Tufenkji, N., Environ. Sci. Technol. 2009, 43, (9), 3176-3182.

32. Fatisson, J.; Domingos, R. F.; Wilkinson, K. J.; Tufenkji, N., Langmuir 2009, 25, (11), 6062-6069.

33. Sirk, K. M.; Saleh, N. B.; Phenrat, T.; Kim, H.-J.; Dufour, B.; Ok, J.; Golas, P. L.; Matyjaszewski, K.; Lowry, G. V.; Tilton, R. D., Environ. Sci. Technol. 2009, 43, (10), 3803-3808.

34. Lang, S.; Wullbrandt, D., Applied Microbiology and Biotechnology 1999, 51, (1), 22-32.

35. Patel, R. M.; Desai, A. J., Journal of Basic Microbiology 1997, 37, (4), 281-286.

36. He, F.; Zhao, D., Environ. Sci.Technol. 2007, 41, (17), 6216-6221. 
37. Liu, Y.; Majetich, S. A.; Tilton, R. D.; Sholl, D. S.; Lowry, G. V., Environ. Sci. Technol. 2005, 39, (5), $1338-1345$.

38. Soberon-Chavez, G.; Lepine, F.; Deziel, E., Applied Microbiology and Biotechnology 2005, 68, (6), 718725.

39. Domingos, R. F.; Baalousha, M. A.; Ju-Nam, Y.; Reid, M. M.; Tufenkji, N.; Lead, J. R.; Leppard, G. G.; Wilkinson, K. J., Environ. Sci Technol. 2009, 43, (19), 7277-7284.

40. Hunter, R. J., Foundations of Colloid Science. In 2nd Ed ed.; 2001; p 806.

41. Sauerbrey, G., Zeitschrift fuer Physik 1959, 155, 206-22.

42. Voinova, M. V.; Jonson, M.; Kasemo, B., Biosensors \& Bioelectronics 2002, 17, (10), 835-841.

43. Voinova, M. V.; Rodahl, M.; Jonson, M.; Kasemo, B., Physica Scripta 1999, 59, (5), 391-396.

44. Elimelech, M.; O'Melia, C. R., Langmuir 1990, 6, (6), 1153-63.

45. Litton, G. M.; Olson, T. M., Colloids and Surfaces: A 1996, 107, 273-83.

46. Pelley, A. J.; Tufenkji, N., Journal of Colloid and Interface Science 2008, 321, (1), 74-83.

47. Tufenkji, N.; Elimelech, M., Environ. Sci. Technol. 2004, 38, (2), 529-536.

48. Nurmi, J. T.; Tratnyek, P. G.; Sarathy, V.; Baer, D. R.; Amonette, J. E.; Pecher, K.; Wang, C.; Linehan, J. C.; Matson, D. W.; Penn, R. L.; Driessen, M. D., Environ. Sci. Technol. 2005, 39, (5), 1221-1230.

49. Chen, K. L.; Elimelech, M., Langmuir 2006, 22, (26), 10994-11001.

50. Chen, K. L.; Elimelech, M., Environ. Sci. Technol. 2008, 42, (20), 7607-7614.

51. Bergna, H. E.; Roberts, W. O., Colloidal Silica: Fundamentals and Applications. [In: Surfactant Sci. Ser.; 2006, 131]. 2006; p 912.

52. Walker, S. L.; Bhattacharjee, S.; Hoek, E. M. V.; Elimelech, M., Langmuir 2002, 18, (6), 2193-2198.

53. Gregory, J., Journal of Colloid and Interface Science 1981, 83, (1), 138-45.

54. Hogg, R.; Healy, T. W.; Fuerstenau, D. W., Transactions of the Faraday Society 1966, 62, (6), 163851.

55. De Gennes, P. G., Advances in Colloid and Interface Science 1987, 27, (3-4), 189-209.

56. Tiraferri, A.; Sethi, R., Journal of Nanoparticle Research 2009, 11, (3), 635-645.

57. Chin, Y.-P.; Aiken, G.; O'Loughlin, E., Environ. Sci. Technol. 1994, 28, (11), 1853-8.

58. Stevenson, I. L.; Schnitzer, M., Soil Science 1982, 133, (3), 179-85. 
59. Herman, D. C.; Artiola, J. F.; Miller, R. M., Environ. Sci. Technol. 1995, 29, (9), 2280-5.

60. Noordman, W. H.; Ji, W.; Brusseau, M. L.; Janssen, D. B., Environ. Sci. Technol. 1998, 32, (12), 1806-1812.

61. Zhang, Y.; Miller, R. M., Applied and Environmental Microbiology 1995, 61, (6), 2247-51.

62. Kretzschmar, R.; Sticher, H., Environ. Sci. Technol. 1997, 31, (12), 3497-3504.

63. Baalousha, M.; Manciulea, A.; Cumberland, S.; Kendall, K.; Lead, J. R., Environmental Toxicology and Chemistry 2008, 27, (9), 1875-1882.

64. Hyung, H.; Fortner, J. D.; Hughes, J. B.; Kim, J.-H., Environ. Sci. Technol. 2007, 41, (1), 179-184.

65. Diegoli, S.; Manciulea, A. L.; Begum, S.; Jones, I. P.; Lead, J. R.; Preece, J. A., Science of the Total Environment 2008, 402, (1), 51-61. 


\section{Figure Captions}

Figure 1. Measured bare nZVI particle size determined using 2 techniques: (a) DLS, and (b) NTA over a range of IS (pH 7) in simple electrolyte ( $\square$ ), with $2 \mathrm{mg} / \mathrm{L} \mathrm{SRFA} \mathrm{( \square ),} \mathrm{and} \mathrm{with} \mathrm{free} \mathrm{CMC}$ $(\diamond)$. Data represent the mean $\pm 95 \%$ confidence interval.

Figure 2. Measured CMC-nZVI particle size determined using 2 techniques: (a) DLS, and (b) NTA over a range of IS (pH 7) in simple electrolyte $(\boldsymbol{\Delta})$, with $2 \mathrm{mg} / \mathrm{L} \operatorname{SRFA}(\triangle)$, and with 2 $\mathrm{mg} / \mathrm{L}$ rhamnolipid $(\nabla)$. Data represent the mean $\pm 95 \%$ confidence interval.

Figure 3. NZVI particle $\zeta$-potential over a range of IS ( $\mathrm{pH} 7)$ under different conditions: (a) for bare nZVI in simple electrolyte $(\boldsymbol{\square})$, with $2 \mathrm{mg} / \mathrm{L} \mathrm{SRFA}(\square)$, with free $\mathrm{CMC}(\diamond)$, and (b) for CMC-nZVI in simple electrolyte ( $\Delta$ ), with $2 \mathrm{mg} / \mathrm{L} \mathrm{SRFA}(\triangle)$, and with $2 \mathrm{mg} / \mathrm{L}$ rhamnolipid $(\nabla)$. Data represent the mean $\pm 95 \%$ confidence interval.

Figure 4. Representative QCM-D measurements (frequency (solid line) and dissipation (dashed line) shifts, $7^{\text {th }}$ overtone $)$ for deposition of bare $\mathrm{nZVI}(150 \mathrm{mg} / \mathrm{L})$ onto $\mathrm{SiO}_{2}$ coated QCM-D crystals in $10 \mathrm{mM} \mathrm{NaHCO}$ at $\mathrm{pH}$ 7. Phase I: baseline upon background electrolyte injection, Phase II: deposition of bare nZVI in same electrolyte, and Phase III: ripening is occurring between deposited and suspended particles.

Figure 5. Average measured values over a range of IS ( $\mathrm{pH} 7$ ) of (a) $-f_{\text {slope, }}$ (b) $D_{\text {slope, }}$ and (c) $m_{\text {slope }}$ determined from the $7^{\text {th }}$ overtone measurements during deposition of nZVI onto silica at different solution conditions: bare nZVI in simple electrolyte (ם), CMC-nZVI in simple electrolyte ( $\mathbf{A})$, 
bare nZVI with free CMC $(\diamond)$, and bare nZVI in simple electrolyte onto CMC coated silica $(\diamond)$. Data represent the mean $\pm 95 \%$ confidence interval.

Figure 6. Calculated DLVO interaction energy profiles for a nanoparticle approaching a flat $\mathrm{SiO}_{2}$ surface in the case of a bare nZVI particle (a and c), a CMC-coated nZVI particle (b, $d$ and e) in simple electrolyte ( $a$ and $b$ ), in the presence of SRFA $2 \mathrm{mg} / \mathrm{L}$ ( $c$ and d) or in the presence of rhamnolipid $2 \mathrm{mg} / \mathrm{L}$ (e). Nanoparticle sizes were taken from DLS measurements (Figures 1a and 2a). Steric contributions were considered in these calculations, except for bare nZVI particles in simple electrolyte (a). Solid lines correspond to $3 \mathrm{mM}$ IS while dashed and dotted lines correspond to 10 and $100 \mathrm{mM}$, respectively.

Figure 7. Average measured values over a range of IS (pH 7) of (a) $-f_{\text {slope }}$, (b) $D_{\text {slope, }}$ and (c) and (d) $m_{\text {slope }}$ determined from the $7^{\text {th }}$ overtone measurements during deposition of nZVI onto silica at different solution conditions: bare nZVI with $2 \mathrm{mg} / \mathrm{L}$ SRFA ( $\square$ ), CMC-nZVI with $2 \mathrm{mg} / \mathrm{L}$ SRFA $(\triangle)$, CMC-nZVI with $2 \mathrm{mg} / \mathrm{L}$ rhamnolipid $(\nabla)$, bare nZVI in simple electrolyte $(\mathbf{\square})$ and CMCnZVI in simple electrolyte $(\boldsymbol{\Delta})$. Selected data from Figures $5 \mathrm{c}$ and $7 \mathrm{c}$ are plotted again in (d) for comparison purpose. Data represent the mean $\pm 95 \%$ confidence interval. 
Figures
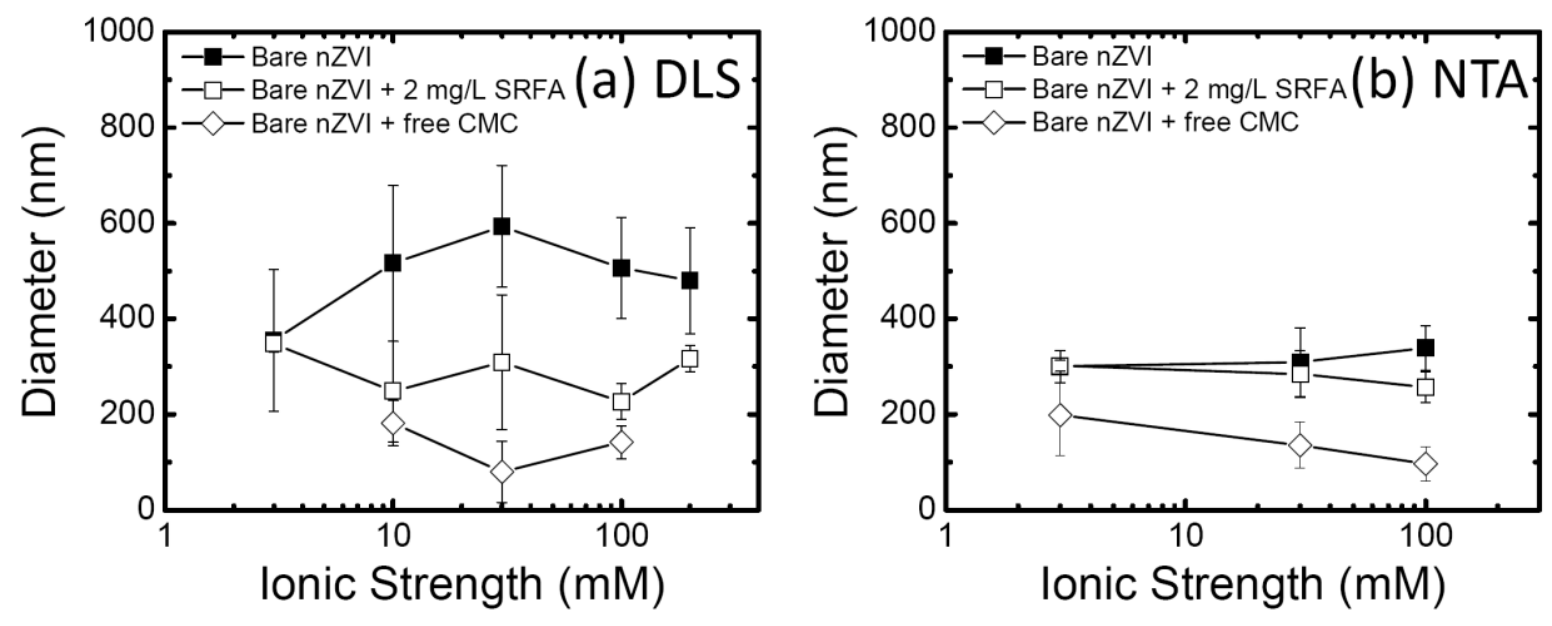

FATISSON et al FIGURE 1 

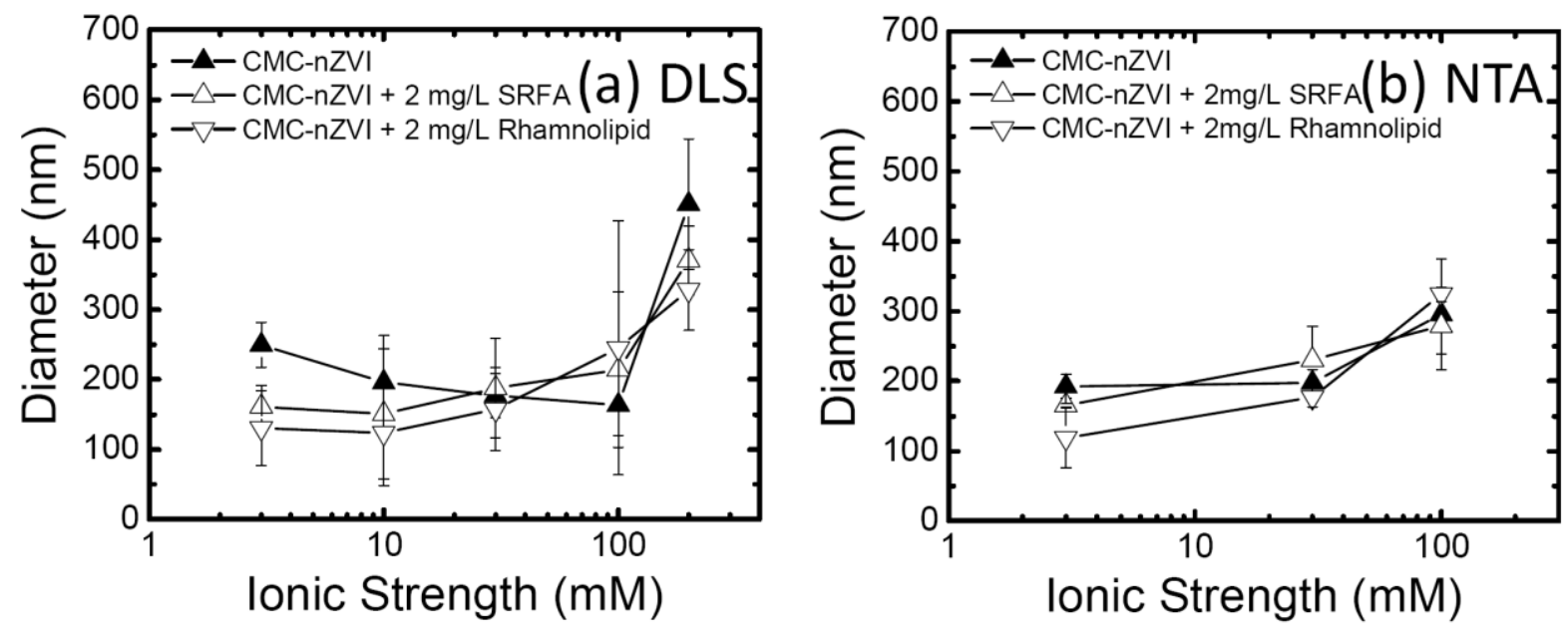

FATISSON et al FIGURE 2 

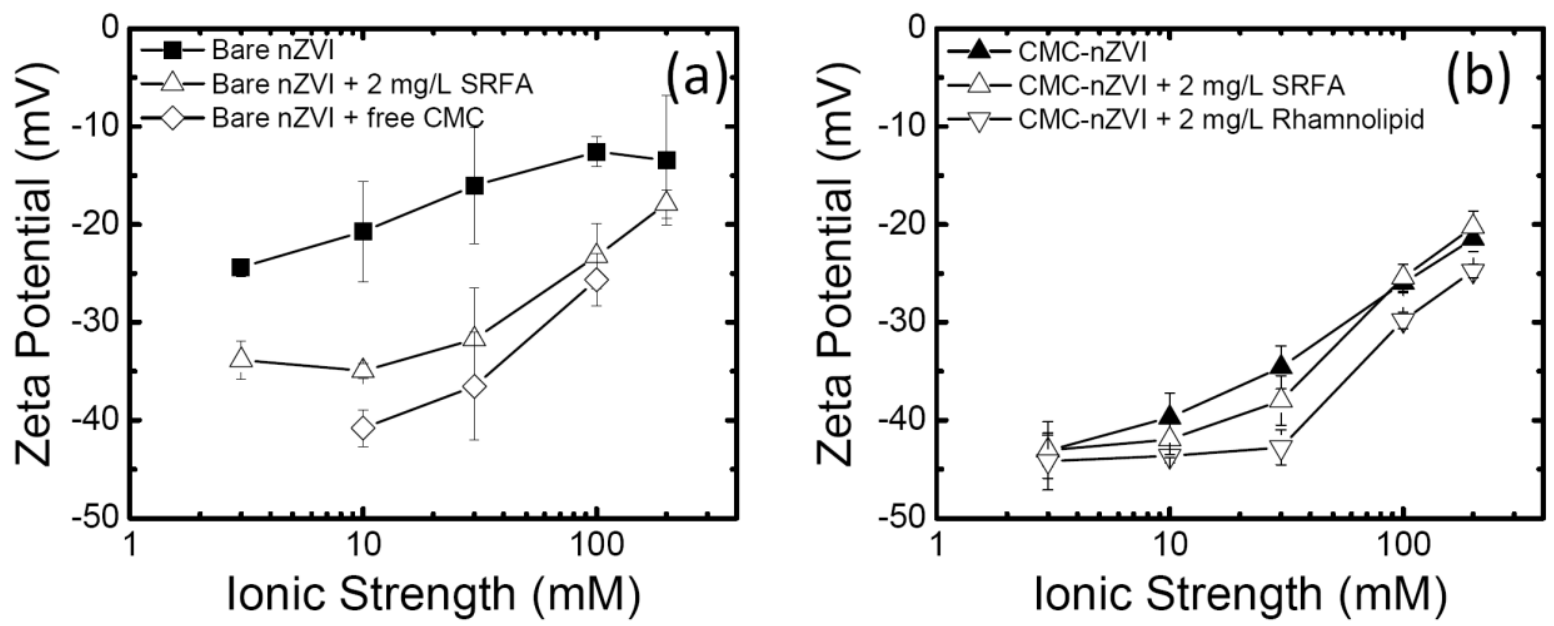

FATISSON et al FIGURE 3 


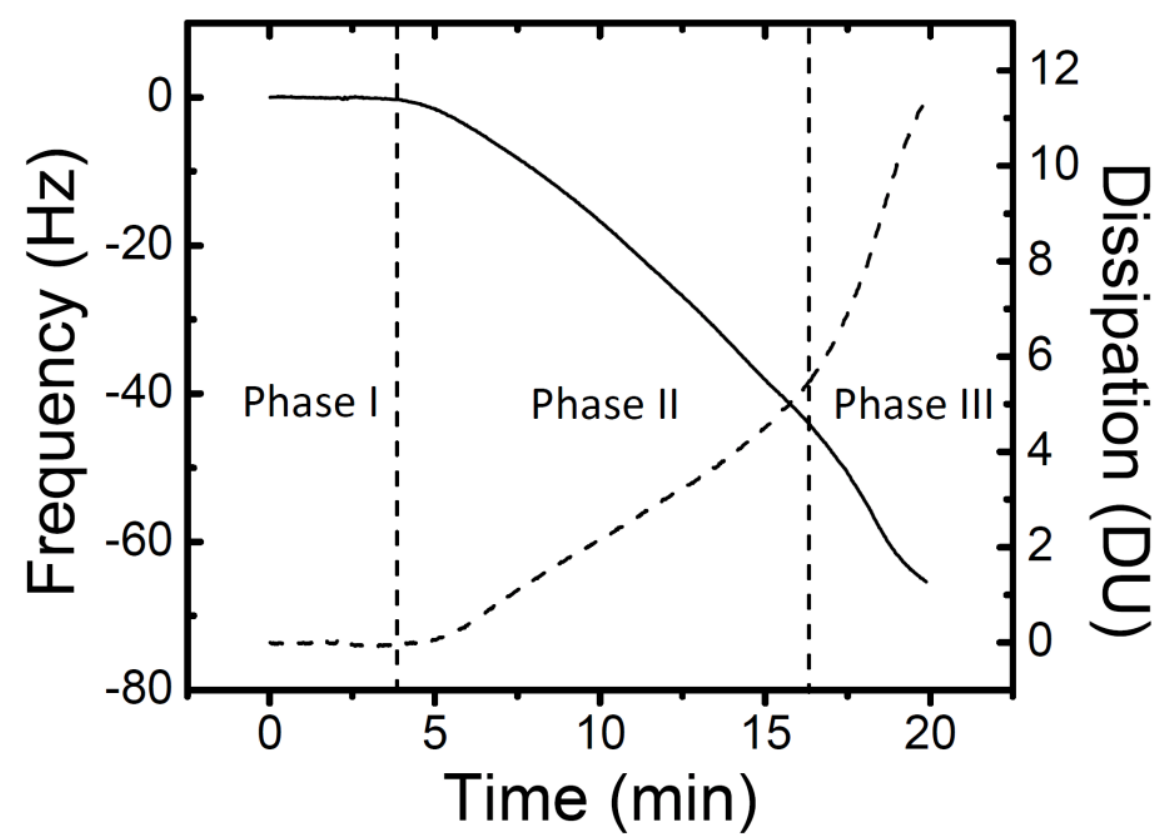

FATISSON et al FIGURE 4 

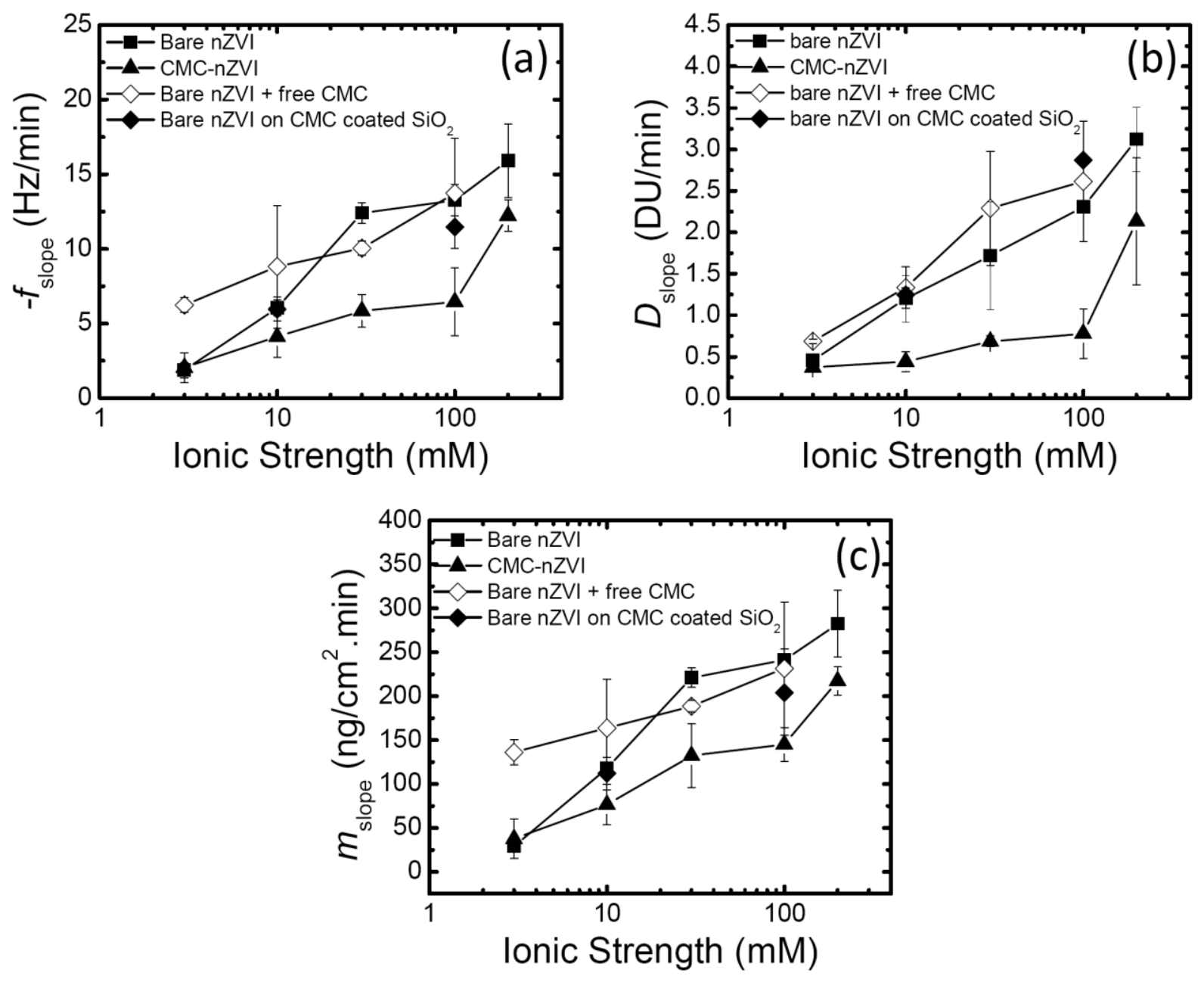

FATISSON et al FIGURE 5 

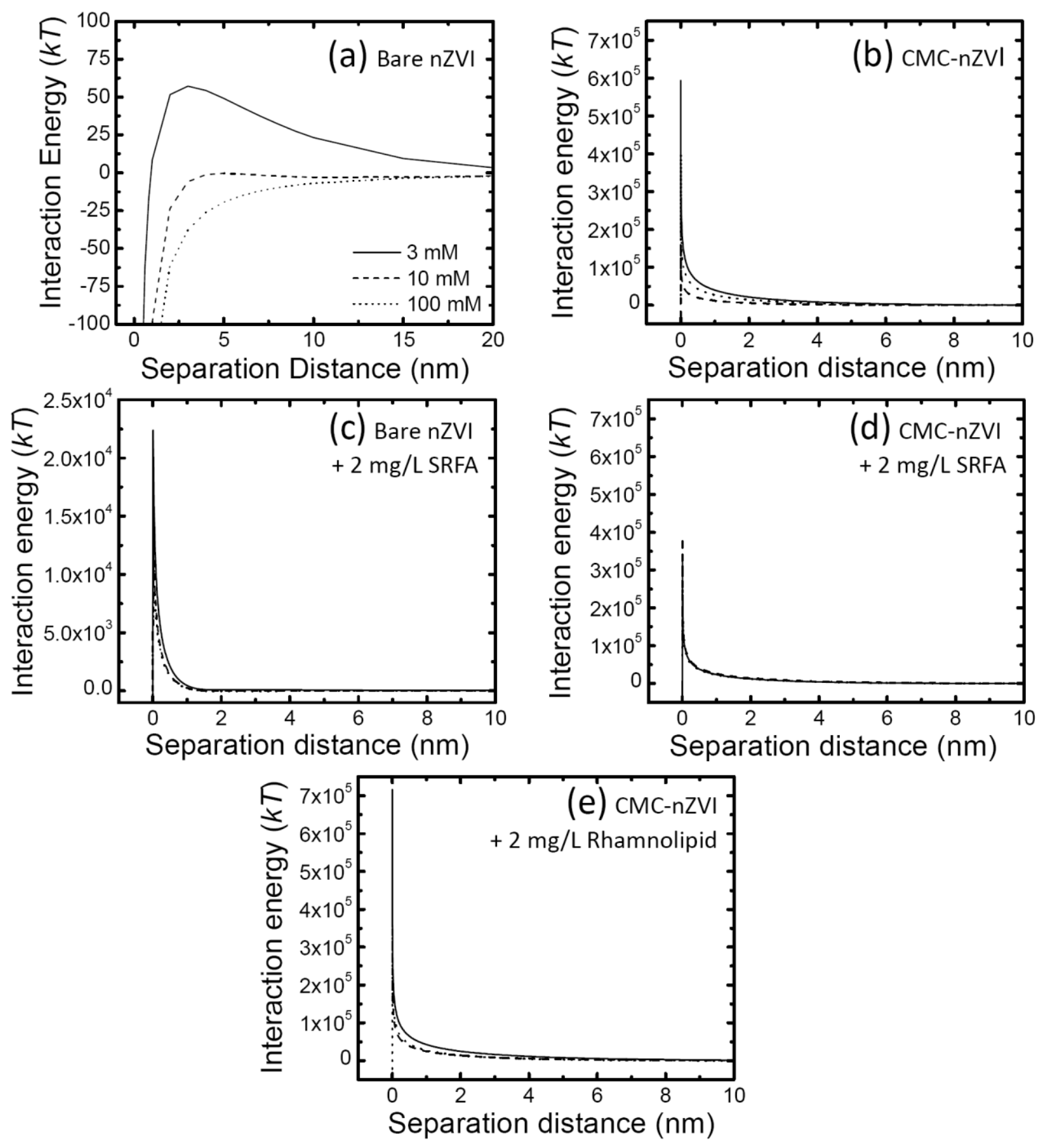

FATISSON et al FIGURE 6 

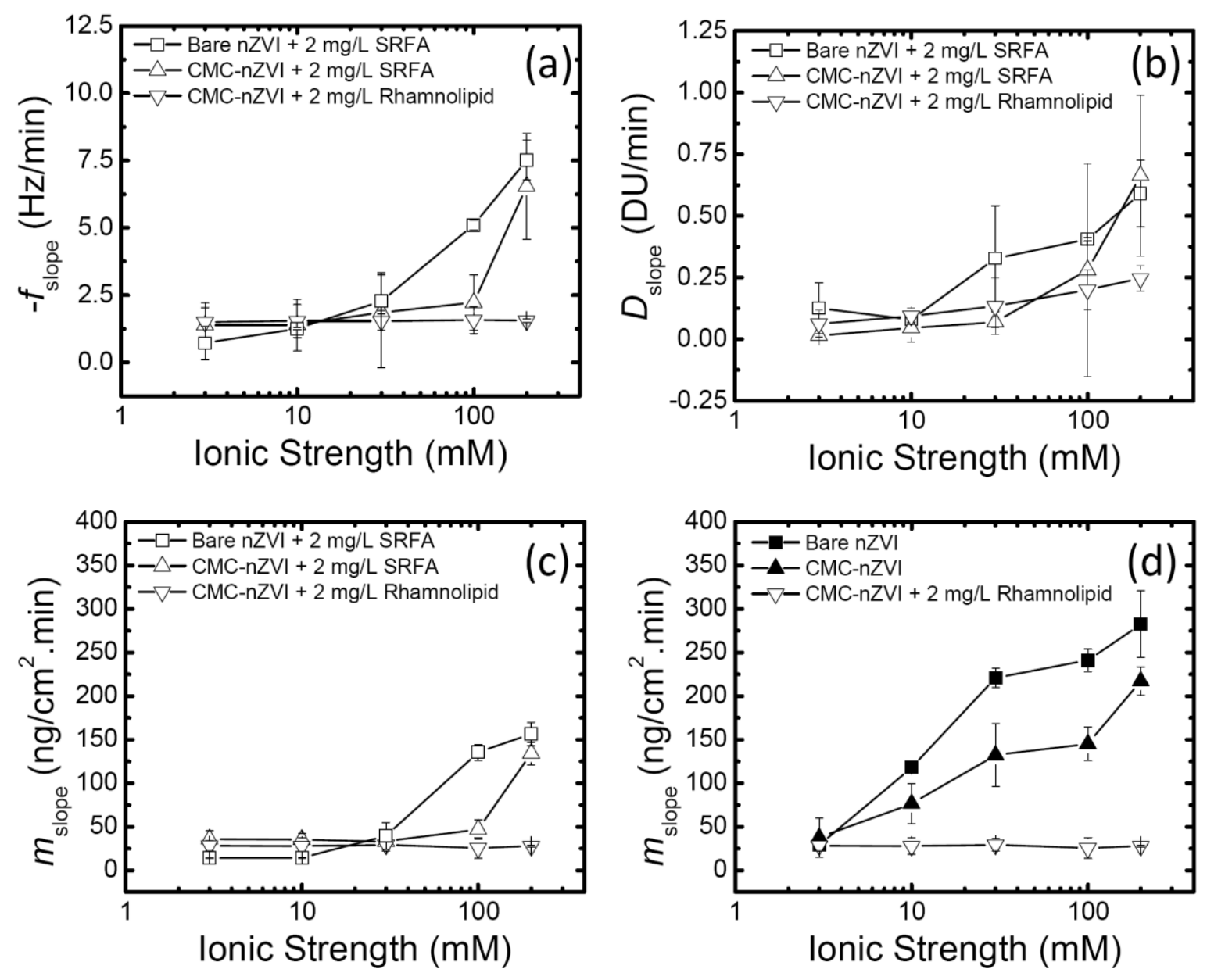

FATISSON et al FIGURE 7 

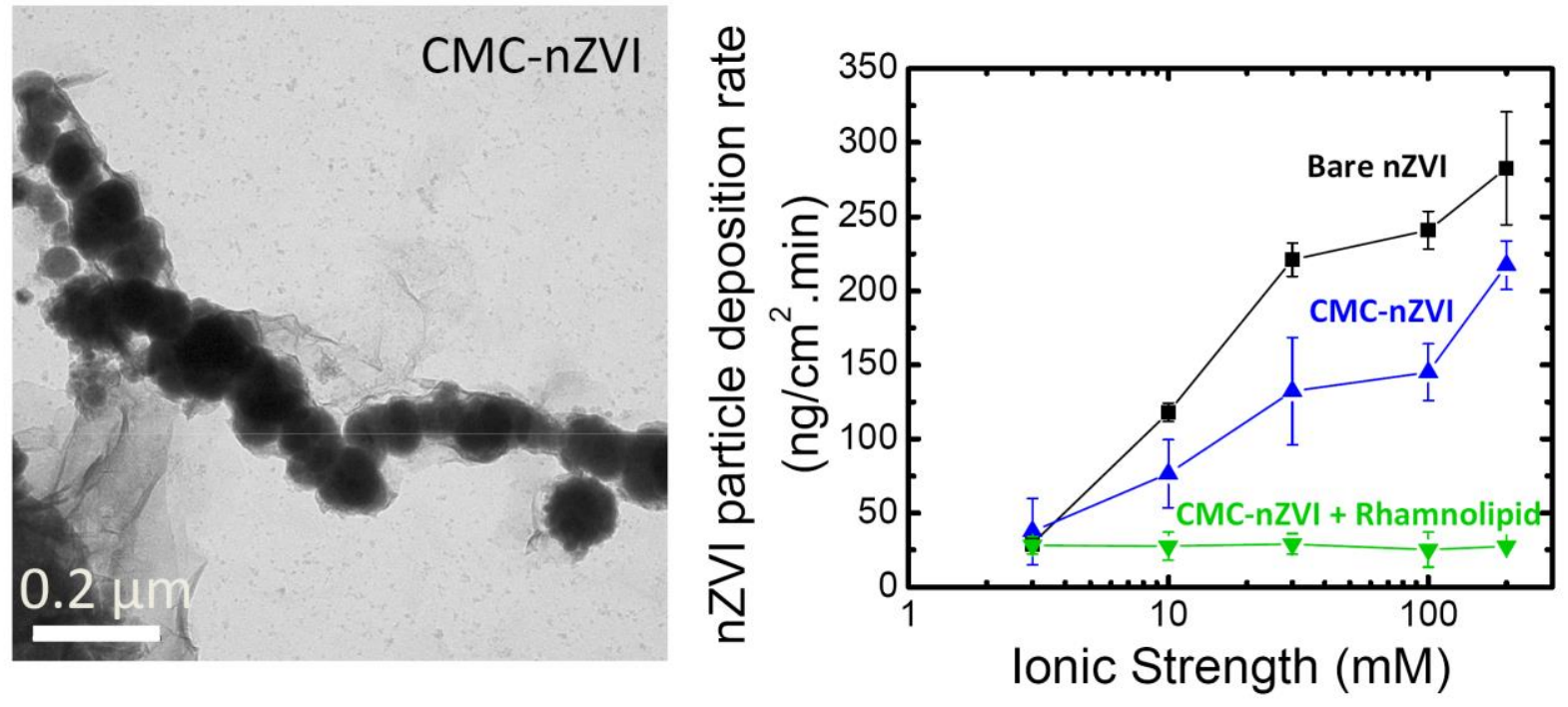

FATISSON et al

FIGURE TOC 